\title{
Análise da Metodologia Alternativa para Recebimento de Biomassa em uma Cooperativa Agroindustrial do Oeste do Paraná
}

\author{
Analysis of Alternative Methods for Biomass Reception on a Cooperative \\ Agroindustrial Paraná West
}

\begin{abstract}
Resumo
O objetivo do estudo foi analisar os resultados financeiros gerados pela aplicação de uma metodologia alternativa para recebimento da biomassa/cavaco em uma cooperativa agroindustrial avícola do oeste do Paraná. Essa metodologia foi concebida como uma forma de promoção do desenvolvimento econômico sem a redução de recursos naturais e geração de mínimos danos ao meio ambiente pelo processo de combustão para aquecimento da caldeira da agroindústria, e tem como base teórica o Relatório Brundtland (1991) e diretrizes básicas das normas caracterizadas pela ISO 14000. Aplicaram-se procedimentos de pesquisas bibliográfica, documental e exploratória, estudo de caso, bem como observação participante. Os resultados foram analisados sob abordagem qualiquantitativa e apontaram que a adoção dessa metodologia diminui custos de produção do vapor na caldeira sem comprometimento à demanda de produção industrial, o que contribui para a agroindústria investigada alcançar desempenho mais sustentável.
\end{abstract}

Palavras-chaves: Biomassa/cavaco. Combustão. Desenvolvimento Sustentável.

\begin{abstract}
The aim of the study was to analyze the financial results generated by the application of an alternative methodology for receipt of biomass / wood chips in a poultry agribusiness cooperative in western Paraná. This methodology was conceived as a way to promote economic development without the reduction of natural resources and generation of minimal damage to the environment by the combustion process for heating the agribusiness boiler, and its theoretical basis the Brundtland Report (1991) and guidelines basic ISO 14001 were applied exploratory research procedures, case studies, literature and documents, as well as participant observation. The results were analyzed in qualitative and quantitative approach and pointed out that this method decreases steam production costs in the boiler without compromising the industrial production demand and contributes to the agribusiness investigated reach more sustainable performance.
\end{abstract}

Key-words: Biomass/chip. Combustion. Sustainable development.

Recebido: 20/04/2014 Aceito: 07/08/2016

Marisa Zeni de Castro Tomasetto ${ }^{1}$ e Rafael Franco de Camargo ${ }^{2}$

${ }^{1}$ UNIOESTE - Campus de Toledo, Mestre em Desenvolvimento Regional e Agronegócios- mzcastro@ hotmail.com- Rua Hilário Zardo, 275 - Sobrado 01 Condomínio Boulevard Residence, Bairro Country Cascavel - PR CEP 85813-330.

${ }^{2}$ Faculdade de Tecnologia INSAEOS , Tecnólogo em Gestão de Cooperativas- Rafael@lar.ind.br. 


\section{Introdução}

A produção avícola destinada ao abastecimento da agroindústria de abate e de processamento de carnes é uma das atividades econômicas de maior expressão no mercado mundial. Nesse contexto, o Brasil se tornou, a partir de 2012, o terceiro produtor mundial de aves e líder da exportação de carnes (BRASIL, 2015).

Conforme a Associação Brasileira de Proteína Animal (ABPA, 2015), em 2014, o Brasil produziu 1,691 milhões de toneladas de carne de frango, crescimento de $3,11 \%$ em relação à produção de 2013. O consumo nacional per capita de carne de frango atingiu 42,78 quilos, mostrando crescimento equivalente a 2,2\% comparado ao índice registrado no ano anterior. Quanto às exportações da agroindústria do frango (inteiro, cortes, processados e congelados), em 2014, o país exportou 3,65 milhões de toneladas, aumento de 2,5\% acima do total exportado no em 2013.

A participação brasileira no comércio internacional de carnes continua a crescer. $\mathrm{O}$ Ministério da Agricultura, Pecuária e Abastecimento, MAPA, estima que até 2020, a produção nacional de carnes (bovina, suína e de frango) suprirá $44,5 \%$ da demanda mundial, em especial a carne de frango que, possivelmente, chegará a 48,1\% da exportação mundial. Dessa forma, o país poderá manter posição de primeiro exportador de carne bovina e de frango (BRASIL, 2015). Todavia, a atividade de produção abate e processamento de carne segue o padrão produtivo mundial, que se caracteriza pela extração de recursos do meio ambiente, necessários à produção de alimentos e bens de consumo. Essas atividades são potencialmente geradoras de resíduos e poluentes que, se não tratados de forma adequada, degradam e esgotam os recursos naturais que, por natureza, têm caráter finito (ARAÚJO e MENDONÇA, 2009).

A preocupação com a degradação do meio ambiente e a finitude dos recursos naturais conduz a inserção desse tema na agenda global, especialmente a partir da Conferência das Nações Unidas, ONU, sobre o Desenvolvimento e Meio Ambiente Humano, CNUMAH, em 1972, realizada em Estocolmo, Suécia. Diante da problemática da escassez dos recursos naturais, em 1991, entra para os debates internacionais o tema desenvolvimento sustentável, do qual se abstrai o conceito de sustentabilidade (BOFF, 2008).

No atual contexto e na perspectiva de desenvolvimento sustentável, a tendência mundial conduz à busca por um processo produtivo que também encontre soluções para a poluição, escassez dos recursos naturais e à miséria do mundo (CORAL, 2002). Para tal, é preciso volver um olhar à natureza e à qualidade de vida do homem e da biodiversidade mundial, o que se constitui, sobretudo, em um dos maiores desafios da humanidade para alcançar a sustentabilidade (HART, 1997).

Conquanto, apesar da consolidação do agronegócio avícola brasileiro, recentemente novos desafios se fazem presentes, como, por exemplo: (a) os crescentes debates teóricos e científicos, com expressão na sociedade em geral, quanto à sustentabilidade ambiental; (b) tendência do mercado mundial no que se refere à requisição de rotulagem e certificações de produtos elaborados sob critérios ambientais como requisitos indispensáveis à importação e à comercialização.

Nesse aspecto, de acordo com a United Nations Environment Program (UNEP, 2015), a agroindústria de abate e processamento de carnes de frango, que assume papel determinante desde a ponta da cadeia produtiva, é impulsionada a comprometer-se com a produção mais limpa ${ }^{1}$. Ou seja, adotar estratégias e políticas adequadas para a gestão de seus relacionamentos com a comunidade produtora da matéria-prima, consumidores de seus produtos e atender às exigências dos mercados potenciais do agronegócio (CORAL, 2002).

Assim, na expectativa de contribuir com o crescimento econômico sustentável e proteção ambiental pela otimização e manutenção da eficiência de combustão em caldeiras industriais, desenvolveu-se esse estudo em uma Unidade Industrial de Aves (UIA), complexo cooperativista agroindustrial do oeste do Paraná, com o objetivo de analisar os resultados financeiros advindos da aplicação da metodologia alternativa para recebimento da biomassa/cavaco sob medida da

\footnotetext{
${ }^{1}$ Expressão usa no Programa das Nações Unidas para o Meio Ambiente, PNUMA, em 1990, para significar a aplicação contínua de uma estratégia ambiental integrada a processos, produtos e serviços para aumentar a eficiência e reduzir os riscos para os seres humanos e o meio ambiente. (UNEP, 2015).
} 
umidade e poder calorífico ${ }^{2}$ na relação comparativa com a biomassa/cavaco medida em volume, $\mathrm{m}^{3} \mathrm{e}$ tonelada.

O escopo principal do estudo centra-se no estudo e quantificação dos ganhos financeiros gerados pela adoção da metodologia de recebimento/pagamento da biomassa/cavaco pela medida de sua umidade e poder calorífico na relação comparativa com a metodologia de recebimento/pagamento da biomassa/cavaco medida em volume, $\mathrm{m}^{3}$, e tonelada.

A motivação para exploração desse tema/assunto proveio da participação dos autores no projeto gestão do consumo de energia elétrica, de combustíveis e vapor, da UIA investigada, que propunha estudo de alternativas para o crescimento sustentável e obtenção de economias substanciais de energia térmica, com pouco investimento, pela alteração na metodologia de recebimento/pagamento do combustível, otimização e manutenção da eficiência de combustão na caldeira.

Além desta introdução (1), apresentam-se a revisão teórica (2) que embasou o estudo, os procedimentos metodológicos (3), os resultados (4) e as considerações finais(5).

\section{Revisão Teórica}

Nas discussões sobre a escassez dos recursos naturais, entrou na agenda dos debates internacionais o conceito de desenvolvimento sustentável, em 1991, com a divulgação do Relatório Brundtland, documento elaborado pela Comissão Mundial sobre Meio Ambiente e Desenvolvimento, criada pela Assembleia das Nações Unidas, ONU, para avaliação das ações desenvolvidas pelos governantes consignatários do acordo firmado na CNUMAH/1972 $2^{3}$ em Estocolmo (BOFF, 2008).

No teor desse documento, desenvolvimento sustentável é definido como modelo de "desenvolvimento que atende às necessidades do presente sem comprometer a possibilidade das gerações futuras em atenderem suas próprias

\footnotetext{
${ }^{2}$ Poder calorífico é definido como a quantidade de calor produzido pela combustão completa de uma unidade de massa de combustível (LIMA, 2010).

${ }^{3}$ Conferência das Nações Unidas sobre Meio Ambiente Humano.
}

necessidades" (BRUNDTLAND, 1991, p. 45). Esse conceito chamou a atenção do mundo para promover novas formas de desenvolvimento econômico, sem redução dos recursos naturais e/ou danos ao meio ambiente. Nesse sentido, o Relatório Brundtland define três princípios básicos: desenvolvimento econômico, proteção ambiental e equidade social (SACHS, 2000).

Embutidos na definição expressa pelo Relatório Brundtland aparecem outros conceitos fundamentais como $\mathrm{o}$ de necessidades, em particular àquelas essenciais dos pobres, as quais se deveria outorgar prioridade preponderante, e o conceito de limitações devidas ao estado da tecnologia e à organização social em correlação com a capacidade do meio ambiente para satisfazer as necessidades presentes e futuras (COSTABEBER e CAPORAL, 2003).

$O$ conceito de necessidades trata da equidade (necessidades essenciais dos pobres). A ideia de limitação se refere às limitações que o estágio da tecnologia e da organização social determina ao meio ambiente. Todavia, as necessidades humanas são determinadas social e culturalmente, mas há o requerimento para promoção de valores com o propósito de manter os padrões de consumo dentro dos limites das possibilidades ecológicas (COSTABEBER e CAPORAL, 2003).

Na concepção do Relatório Brundtland (1991), o desenvolvimento sustentável implica compatibilidade do crescimento econômico, com desenvolvimento humano e qualidade ambiental. Daí porque as sociedades devem atender às necessidades humanas em dois sentidos: aumentar o potencial de produção e assegurar a todos as mesmas oportunidades, o que inclui gerações presentes e futuras. Nessa ótica, o desenvolvimento sustentável não se constitui em estado permanente de equilíbrio quanto ao acesso aos recursos e à distribuição de benefícios e custos, mas em um estado de mudanças constantes. Na essência, de acordo com o Relatório Brundtland, desenvolvimento sustentável,

é um processo de transformação no qual a exploração dos recursos, a direção dos investimentos, a orientação do desenvolvimento tecnológico e a mudança institucional se harmonizam e reforçam o potencial presente e futuro, a fim de atender às necessidades e às aspirações humanas (1991, p. 49). 
A definição de sustentabilidade, retirada do Relatório Brundtland (1991) com base no conceito de desenvolvimento, significa a possibilidade de se obterem continuamente condições iguais ou superiores de vida para um grupo de pessoas e seus sucessores em dado ecossistema. Contudo, a "sustentabilidade deve ser vista, estudada e proposta como sendo permanente busca de novos pontos de equilíbrio entre diferentes dimensões que podem ser conflitivas entre si em realidades concretas" (CAPORAL e COSTABEBER, 2002, p. 75).

Nesse sentido, define-se sustentabilidade como a capacidade de um agroecossistema se manter socioambientalmente produtivo ao longo do tempo, sendo algo relativo que pode ser medido somente ex post. Essa definição expressa a multidimensionalidade desse conceito e forma um novo conceito o de sustentabilidade total que referese àquela ideia de que o crescimento econômico pode ser sustentável com a reestruturação ecológica das modernas instituições como: mercado, Estado, ciência e tecnologia e sociedade civil (SACHS, 2000; CORAL, 2002; CAVALCANTI, 2003).

A seguir, descreve-se, brevemente, o significado de cada uma das dimensões da sustentabilidade, quais sejam: social, ecológica, espacial ou territorial, ambiental econômica, ecológica, cultural, ética e política.

Sustentabilidade na dimensão social diz respeito à melhoria da qualidade de vida da população, à equidade na distribuição de renda e à diminuição das diferenças sociais, com participação e organização popular (SACHS, 2000). Essa dimensão representa um de seus pilares básicos porque preservação ambiental e conservação dos recursos naturais só adquirem significado $\mathrm{e}$ relevância quando o produto gerado, em bases renováveis, também possa ser equitativamente apropriado e usufruído pelos diversos segmentos sociais (CORAL, 2002). Sob o ponto de vista temporal, a noção de equidade se relaciona com intrageracional, ou seja, a disponibilidade de sustento mais seguro para a presente geração, e intergeracional, exatamente porque não se pode comprometer hoje o sustento seguro das gerações futuras (CAPORAL e COSTABEBER, 2002).

A dimensão social da sustentabilidade inclui, também, a busca contínua de melhores níveis de qualidade de vida mediante produção e consumo de alimentos com qualidade biológica superior, o que comporta, dentre outras ações, a eliminação do uso de insumos tóxicos no processo produtivo agrícola mediante novas combinações tecnológicas, ou ainda, por meio de opções sociais de natureza ética ou moral. Nesse caso, é a própria percepção de riscos e/ou efeitos maléficos do uso de tecnologias sobre as condições sociais das famílias agrícolas que determina ou origina novas formas de relacionamento da sociedade com o meio ambiente, um modo de estabelecer uma conexão entre a dimensão social e a ecológica, sem prejuízo da dimensão econômica (CAPORAL e COSTABEBER, 2002).

Sustentabilidade na dimensão ecológica refere-se à base física do processo de crescimento e tem por objetivo a manutenção de estoques dos recursos naturais, incorporados as atividades produtivas (SACHS, 2000). Essa dimensão encontra significado quando o uso dos recursos naturais minimizam danos aos sistemas de sustentação da vida e isto ocorre por meio da redução dos resíduos tóxicos e da poluição, da reciclagem de materiais e energia, da conservação e manutenção de tecnologias limpas e de maior eficiência e regras para uma adequada proteção ambiental. Todavia, nessa e em outras dimensões, para haver sustentabilidade é fundamental garantir as condições físico-químicas e ecológicas que sustentam a (re)produção da vida e da civilização (BOFF, 2008). Essa dimensão é constituída por ações que visam à manutenção e à recuperação da base de recursos naturais, sobre a qual se sustentam e se estruturam a vida e a reprodução das comunidades humanas e demais comunidades de seres vivos (CAPORAL e COSTABEBER, 2002).

A dimensão espacial ou territorial da sustentabilidade trata da necessidade da promoção do equilíbrio entre o rural e o urbano, o equilíbrio de migrações, a desconcentração das metrópoles, a adoção de práticas agrícolas mais inteligentes e não agressivas à saúde dos seres vivos e ao ambiente, manejo sustentado de recursos hídricos e florestas e a industrialização descentraliza (SACHS, 2000). Tal dimensão se liga ao conceito de territorialidade, isto é, o espaço territorialmente ocupado pelo homem e defendido contra os membros de sua própria espécie. É a dimensão norteadora da equidade nas relações inter-regionais (BRASIL, 
2000) para a promoção do desenvolvimento sustentável local (SILVA e MENDES, 2005).

A dimensão ambiental da sustentabilidade refere-se "à manutenção da capacidade de sustentação dos ecossistemas, o que implica a capacidade de absorção e recomposição dos ecossistemas em face das agressões antrópicas" (BRASIL, 2000, p. 31). Conservação geográfica, equilíbrio de ecossistemas, erradicação da pobreza e da exclusão, respeito aos direitos humanos e integração social fazem parte dessa dimensão, abarcando, de certa maneira, por meio de seus processos complexos, todas as dimensões do próprio conceito de sustentabilidade. $\mathrm{Na}$ abordagem do desenvolvimento sustentável local, a dimensão ambiental é fundamental para garantir a preservação das condições de sobrevida das espécies ligadas à flora e fauna do ambiente local (SILVA e MENDES, 2005).

Sustentabilidade na dimensão econômica diz respeito aos setores produtivos públicos e privados, regularização do fluxo desses investimentos, compatibilidade entre padrões de produção e consumo, equilíbrio do balanço de pagamento, acesso à ciência e à tecnologia (SACHS, 2000). Essa dimensão refere-se à gestão eficiente dos recursos em geral e se caracteriza pela regularidade de fluxos do investimento público e privado, implicando na avaliação "da eficiência por processos macrossociais" (BRASIL, 2000, p. 31). Então, há que se pensar na organização da sociedade: como, para quem e o que produzir, de que modo para satisfazer às necessidades dos cidadãos. Mesmo ligada à economia, tal organização não pode prescindir às outras dimensões do conceito de sustentabilidade e nem a abordagem de desenvolvimento sustentável local (SILVA e MENDES, 2005).

Sustentabilidade na dimensão cultural refere-se ao respeito pelos diferentes valores entre os povos e incentivo a processos de mundança que acolham especificidades locais. São os saberes, os conhecimentos e os valores locais das populações que precisam ser analisados, compreendidos e utilizados como ponto de partida nos processos de desenvolvimento a fim de espelhar a 'identidade cultural' dos povos e das pessoas que vivem e trabalham nas comunidades (SACHS, 2000).

Essa face da dimensão cultural não deve obscurecer a necessidade de um processo de problematização sobre os elementos formadores da cultura de determinado grupo social. Todavia, não se deve estimular práticas culturalmente agressivas ao meio ambiente e prejudiciais ao fortalecimento das relações sociais e às estratégias de ação social coletiva (CAPORAL e COSTABEBER, 2002).

Sustentabilidade na dimensão ética relaciona-se diretamente à solidariedade intra e intergeracional e com novas responsabilidades dos indivíduos em respeito à preservação do meio ambiente (CAPORAL e COSTABEBER, 2002). Entretanto, vive-se uma crise socioambiental, exatamente porque a história da natureza não é só ecológica, é também social. Por tal razão, qualquer novo contrato ecológico deve ser acompanhado do respectivo contrato social, o qual terá como ponto de partida uma profunda crítica sobre as bases epistemológicas que sustentaram o surgimento dessa crise. Essa dimensão ética exige pensar e fazer viável a adoção de novos valores, que não necessariamente sejam homogêneos (GUIMARÃES, 2002).

Sustentabilidade na dimensão política se associa ao processo de construção da cidadania para garantir a incorporação plena dos homens ao processo de desenvolvimento. No Brasil, essa dimensão se liga à evolução da democracia representativa para sistemas descentralizados e participativos, construção de espaços públicos comunitários, autonomia dos governos locais e descentralização da gestão de recursos (SACHS, 2000; SILVA e MENDES, 2005). Porquanto, refere-se aos métodos e às estratégias participativas capazes de assegurar o resgate da autoestima e o pleno exercício da cidadania (CAPORAL e COSTABEBER, 2002).

Em conjunto, as Conferências da ONU, especialmente a partir da ECO/1992, ocorrida no Rio de Janeiro, Brasil, assumiram papel fundamental na disseminação dos conceitos expressos no Relatório Brundtland (1991), assim como abriram espaços para ingresso de novos atores no campo ambiental (BOFF, 2008).

A partir da atuação desses novos atores, no campo ambiental observaram-se sensíveis avanços na ecodiplomacia e promoção de convenções internacionais para discussão sobre problemas ambientais de âmbito global; sensibilização ambiental difusa na sociedade e consequente crescimento de demandas e mobilização social; 
mudanças de atitudes em empresas públicas ou privadas que, pela adoção de mecanismos de gestão ambiental, perceberam a probabilidade de mercado, primeiramente, e, posteriormente, enfrentaram barreiras à entrada; fortalecimento da atuação das administrações locais em direção ao resgate da dimensão local em contraposição à acelerada globalização (MAGRINI, 2001; POMBO e MAGRINI, 2008).

Especialmente em torno do movimento de gestão ambiental privada surge a família de normas ISO $14000^{4}$ com ferramentas de gerenciamento para o controle de questões ambientais e melhoria de desempenho ambiental das empresas (ABNT, 2004). Juntas, essas ferramentas oferecem benefícios econômicos e ambientais pela redução no uso de matérias-primas, consumo de energia, geração de rejeitos e custos de disposição; melhoria da eficiência no processo produtivo, gerenciamento de rejeitos pelo uso de reciclagem e incineração para tratamento de resíduos sólidos ou técnicas mais eficientes para o tratamento de efluentes líquidos.

\section{Metodologia}

O presente trabalho caracteriza-se como pesquisa exploratória, estudo de caso, apoiada por pesquisas bibliográfica e documental e técnica de observação participante, sendo os resultados analisados sob abordagem quali-quantitativa.

Conceitualmente, a pesquisa exploratória tem por objetivo proporcionar visão geral, de tipo aproximativo, sobre determinado fato, e suas técnicas auxiliaram o pesquisador a aproximar-se do real, analisá-lo e "desenvolver, esclarecer e modificar conceitos e ideias, tendo em vista a

\footnotetext{
${ }^{4}$ A ISO 14000 é uma norma elaborada pela International Organization fo Standardization, com sede em Genebra, Suíça, que reúne mais de 100 países com a finalidade de criar normas internacionais. Cada país possui um órgão responsável por elaborar suas normas. No Brasil é a Associação Brasileira de Normas Técnicas, ABNT. Para o escopo desse estudo, mencionam-se a norma ISO 14001, que indica requisitos com orientações à gestão ambiental, e a norma ISO 14004, que contém diretrizes gerais sobre princípios, sistemas e técnicas de apoio à gestão ambiental (ABNT, 2004; 2005). Dessas normas retiram-se as categorias de análise: prevenção e controle da poluição, uso racional de recursos naturais, atendimento à legislação ambiental, promoção da sustentabilidade empresarial e melhoria contínua do sistema de gestão ambiental.
}

formulação de problemas mais precisos ou hipóteses pesquisáveis para estudos posteriores" (GIL, 2008, p. 27).

Optou-se pelo procedimento de estudo de caso e abordagens qualitativa e quantitativa para explorar, de forma mais adequada, a realidade pretendida, gerar, coletar e analisar o material obtido. $\mathrm{O}$ estudo de caso consiste em um "estudo profundo e exaustivo de um ou de poucos objetos, de maneira a permitir o seu conhecimento amplo e detalhado, tarefa praticamente impossível mediante os outros tipos de delineamentos considerados" (GIL, 2008, p. 57).

Esse estudo de caso teve como objeto de investigação uma unidade industrial de aves, UIA, complexo cooperativista, localizado na região oeste do Paraná, e como lócus as planilhas de produção industrial e de custos da geração de energia térmica referentes ao período de janeiro de 2011 a agosto de 2015.

$\mathrm{Na}$ abordagem qualitativa "predominantemente pondera, sopesa, analisa e interpreta dados relativos à natureza dos fenômenos, sem que os aspectos quantitativos sejam a sua preocupação precípua" (RODRIGUES, 2007, p. 38). A abordagem quantitativa se preocupa em analisar dados quantificáveis e com o uso de técnicas de estatística aplicada para analisá-los (RODRIGUES, 2007). Nesse estudo, a análise qualitativa centrou-se na geração de energia térmica com menor potencial para causar danos ambientais. Já análise quantitativa mensurou os custos da geração de energia térmica produzida na UIA investigada pela combustão de biomassa dos tipos lenha e cavaco.

A pesquisa bibliográfica, usada na busca de aporte teórico, caracteriza-se pelo uso de fontes secundárias, isto é, de materiais já publicados. Portanto, "abrange toda bibliografia já tomada pública em relação ao tema de estudo" (MARCONI e LAKATOS, 2007, p. 185). A pesquisa documental, utilizada na geração de dados analíticos nesse estudo, tem como foco de análise documentos que abordam o assunto/tema de interesse do pesquisador e que ainda servem de material de análise (GIL, 2008).

A observação participante, ou observação ativa, consiste na participação real do conhecimento na vida da comunidade, do grupo ou de determinada situação, e define-se "como a técnica pela qual se 
chega ao conhecimento da vida de um grupo a partir do interior dele mesmo" (GIL, 2008, p. 103).

Na UIA investigada, a observação participante ocorreu entre outubro de 2014 a agosto de 2015 concomitantemente com a realização do projeto gestão do consumo de energia elétrica, de combustíveis e vapor, bem como o período teste de implantação da sistemática de recebimento da biomassa/cavaco com avaliação da umidade e do poder calorífico.

A análise do material coletado correlacionou impactos financeiros e socioambientais gerados pela sistemática de recebimento/pagamento da biomassa/cavaco pela medida da umidade e poder calorífico na relação comparativa com a sistemática de recebimento/pagamento da biomassa/cavaco medida em volume, $\mathrm{m}^{3}$ e tonelada. Para efeito dessa análise, atualizaram-se as planilhas de custos por toneladas de vapor produzido, custo /tonelada de vapor em reais, referentes ao período de janeiro de 2011 a dezembro de 2014, pelo índice percentual médio anual, reais $/ \mathrm{m}^{3}$, dos produtos florestais destinados à indústria e energia, divulgados pelo Instituto de Economia Agrícola (IEA-APTA, 2015).

\section{Resultados E Discussão}

A responsabilidade socioambiental das cooperativas é definida no arcabouço legislativo brasileiro, que as caracteriza como sociedades de pessoas, cujo objetivo é a prestação de serviços aos associados, os quais se obrigam, reciprocamente, a contribuir com bens e serviços para o exercício de uma atividade econômica, sem objetivar o alcance de lucro (BRASIL, 1971).

A dimensão social da sustentabilidade, expressa nos respectivos estatutos das sociedades cooperativas, caracteriza-se pela democracia, por mecanismos de participação, gestão e de controle dos associados a fim de que ocorra a participação democrática nos processos decisórios. "As ações de responsabilidade social das cooperativas não são esporádicas e nem têm por objetivo o marketing para alcançar maior credibilidade", demandam de seus princípios (KOSLOVSKI, 2006, p. 3 ).

Quanto à dimensão ambiental da sustentabilidade, as cooperativas se defrontam com problemas ambientais, comuns a todas as sociedades, decorrentes do padrão de produção e consumo. Em suas práticas, observam os princípios da Constituição Federal de 1988, com atenção especial à proteção/prevenção de danos ao meio ambiente, art. 225 (BRASIL, 1988), na legislação que dispõe sobre a política nacional do meio ambiente (BRASIL, 1981) e um conjunto de normas internacionais caracterizadas como ISO 14000.

Notadamente, a geração de energia térmica pela combustão de biomassa ocasiona problemas que afetam dimensões de sustentabilidade, cujo conceito está embutido na definição de desenvolvimento sustentável do Relatório Brundtland (1991). Na agroindústria investigada há constante busca pela adoção de tecnologias de produção mais limpas (UNEP, 2015), gestão ambiental adequada, diminuição de custos e promoção do desenvolvimento sustentável, cuja abrangência social extrapola os limites do território nacional, uma vez que, em 2014, esse complexo agroindustrial exportou $54,55 \%$ do total de sua produção anual (AVISITE, 2015).

A aquisição da biomassa/cavaco para o aquecimento da caldeira ${ }^{5}$ da UIA, no período de 2011 a 2014, era efetuada em volume, $\mathrm{m}^{3}$, sem preocupação com a umidade e o poder calorífico do material combustível recebido. Em observância à norma ISO 14001, a partir do estudo elaborado por um grupo profissional multidisciplinar, em 2015 foi posto em prática uma metodologia alternativa para recebimento/pagamento da biomassa/cavaco, que consiste em avaliar a umidade da biomassa/cavaco no ato do recebimento e efetuar o pagamento segundo critérios técnicos em correção com a eficiência da caldeira e o custo do vapor produzido em toneladas. Tais critérios técnicos consideram as características da biomassa/cavaco intrínsecas, capacidade calorífica e densidade (poder calorífico útil), e a extrínseca, a umidade. Tais características afetam o rendimento energético, ou seja, o vapor produzido, e contribuem para a emissão de poluentes na atmosfera (SALUM, 2011).

$\mathrm{Na}$ UIA, devido à adoção dessa sistemática alterativa, no recebimento da biomassa/cavaco, a avaliação da umidade e do poder calorífico é feita

\footnotetext{
${ }^{5}$ Conforme a NR 13,"caldeiras a vapor são equipamentos destinados a produzir e acumular vapor sob pressão superior à atmosférica, utilizando qualquer fonte de energia [...]". (BRASIL, 2014). Para produzir vapor superaquecido, a UIA adota o sistema de caldeira modelo aquatubular. Nesse modelo, a água fica dentro de tubos e coletores (ARRUDA, 2009).
} 
por um equipamento específico, balde medidor $\mathrm{M}$ 75, da Empresa Marrari.

No mercado brasileiro, apesar dos baixos índices de emissões de poluentes atmosféricos, a oferta de biomassa/cavaco com combustível de caldeiras industriais ainda é restrita. Para atender sua demanda, a UIA firmou contrato com uma empresa produtora, não situada no Estado do Paraná, para fornecer regulamente biomassa/cavaco adequada para a combustão e produção de energia térmica em caldeiras industriais.

A tabela 1, a partir de sete diferentes percentagens de umidade, correlaciona à eficiência da caldeira da UIA, parâmetro estimado em $80 \%$, com as variáveis características intrínseca e extrínseca da biomassa e quantidade de vapor produzido por $\mathrm{m}^{3}$ na combustão da biomassa/cavaco que é utilizada no processo de combustão para a geração de vapor pela caldeira industrial.

$\mathrm{Na}$ análise dos valores apresentados na tabela 1 , observa-se que o poder calorífico útil ${ }^{6}$ é inversamente proporcional à densidade e à umidade da biomassa/cavaco, ou seja, quanto menor for a densidade da biomassa/cavaco, maior será o poder calorífico útil, e quanto maior a umidade da biomassa/cavaco, menor será a energia aproveitada durante a combustão. Durante o processo de combustão, parte da energia liberada destina-se à evaporação da água que está armazenada na biomassa/cavaco, em consequência, há diminuição do poder calorífico superior ${ }^{7}$ do material combustível (LIMA, 2010). Então, maior percentagem de umidade influência de forma negativa no calor liberado pelo processo de combustão, uma vez que diminui a eficiência energética do sistema e aumenta a emissão de poluentes atmosféricos (ARRUDA, 2009; SALUM, 2011).

\footnotetext{
6 No poder calorífico útil ou poder calorífico líquido é descontada a energia necessária para a evaporação da água armazenada na biomassa/cavaco (LIMA, 2010, p. 2). 7 Poder calorífico superior refere-se à quantidade de calor liberado pela combustão, de modo que a água proveniente dessa queima esteja em estado líquido (volume constante) (LIMA, 2010, p. 1).
}

Tabela 1 - Eficiência da caldeira e características da biomassa/cavaco

\begin{tabular}{c|c|c|c}
\hline $\begin{array}{c}\text { Umidade da } \\
\text { biomassa/ } \\
\text { cavaco } \\
\text { (em \%) }\end{array}$ & $\begin{array}{c}\text { Poder } \\
\text { calorífico } \\
\text { útil da } \\
\text { biomassa/ } \\
\text { cavaco } \\
\text { (em kcal/kg) }\end{array}$ & $\begin{array}{c}\text { Densidade } \\
\text { da } \\
\text { biomassa/ } \\
\text { cavaco } \\
\left(\mathrm{em} \mathrm{kg} / \mathrm{m}^{2}\right)\end{array}$ & $\begin{array}{c}\text { Vapor } \\
\text { produzido/m } \\
\text { de biomassa/ } \\
\text { cavaco } \\
\text { (em tonelada) }\end{array}$ \\
\hline 20 & $3.542,00$ & 235,00 & 1,11 \\
25 & $3.293,00$ & 265,00 & 1,16 \\
30 & $3.044,00$ & 300,00 & 1,22 \\
35 & $2.794,00$ & 335,00 & 1,25 \\
40 & $2.545,00$ & 365,00 & 1,24 \\
45 & $2.294,00$ & 395,00 & 1,21 \\
50 & $2.044,00$ & 430,00 & 1,17 \\
\hline
\end{tabular}

Fonte: EcoForte (2014).

Em função dessa metodologia para recebimento da biomassa/cavaco, a partir de 2015, a UIA paga somente pela energia útil consumida na combustão para aquecer a caldeira industrial, o que resulta em ganho financeiro para a indústria. Essa afirmativa pode ser observada na tabela 2 que, desconsiderada a variável densidade, relaciona a umidade do material combustível, com o vapor produzido na caldeira da UIA, eficiência estimada em $80 \%$, e custo desse vapor calculado a partir do preço da biomassa/cavaco (reais por tonelada).

Verifica-se, na tabela 2, que o valor pago pela UIA para a biomassa/cavaco é inversamente proporcional à umidade, ou seja, quanto menor for a percentagem da umidade, maior será o valor pago pela tonelada da biomassa/cavaco. Ainda que haja aumento do custo do vapor produzido, menor umidade da biomassa/cavaco evita perdas energéticas, gera aumento da eficiência energética do sistema de combustão e menor emissão de poluentes atmosféricos. Lembra-se que a eficácia do sistema de combustão diminui a liberação, pela chaminé, de combustível gasoso, monóxido de carbono e átomos de carbono sob a forma de fuligem (SALUM, 2011). 
Tabela 2 - Custo da produção do vapor

\begin{tabular}{c|c|c|c}
\hline $\begin{array}{c}\text { Umidade da } \\
\text { biomassa/cavaco } \\
(\mathrm{em} \%)\end{array}$ & $\begin{array}{c}\text { Vapor produzido/ } \mathrm{m}^{3} \mathrm{de} \\
\text { biomassa/cavaco } \\
\text { (em tonelada) }\end{array}$ & $\begin{array}{c}\text { Custo /tonelada } \\
\text { de vapor } \\
\text { (em reais) }\end{array}$ & $\begin{array}{c}\text { Valor pago pela } \\
\text { biomassa/cavaco } \\
\text { (reais/tonelada) }\end{array}$ \\
\hline 20 & 1,11 & 41,411872 & 279,85 \\
25 & 1,16 & 39,500599 & 245,28 \\
30 & 1,22 & 37,746386 & 16,45 \\
35 & 1,25 & 36,827316 & 178,08 \\
40 & 1,24 & 37,107409 & 164,55 \\
50 & 1,21 & 38,040899 & 151,16 \\
\hline
\end{tabular}

Fonte: Dados da pesquisa (2015)

Nesse estudo, já se evidenciou que entre 2011 até 2014, a sistemática de recebimento/pagamento da biomassa/cavaco, adotada pela UIA, desconsiderava a umidade e o poder calorífico do material utilizado como combustível. $\mathrm{Na}$ análise correlacional entre o custo do vapor produzido na UIA pela adoção da sistemática de recebimento/pagamento da biomassa/cavaco adotada até 2014 e custo do vapor produzido pela sistemática de recebimento/pagamento da biomassa/cavaco por umidade e poder calorífico, adotada em 2015, verifica-se significativa variação. Essa variação é observada no gráfico 1, elaborado a partir da média da produção industrial da UIA e considerada a variação da umidade da biomassa/cavaco nos parâmetros entre $20 \%$ e $35 \%$ e nos anos circunstanciados.

No gráfico 1, nota-se que, em 2015, o maior custo da produção de vapor da UIA ocorreu no mês de fevereiro, período de implantação da sistemática de recebimento/pagamento da biomassa/cavaco pela medida da umidade e poder calorífico, e atingiu $\mathrm{R} \$$ 80,00/Tonelada. Em outubro de 2011 e julho de 2013 , esse custo atingiu $\mathrm{R} \$ 104,43 /$ Toneladas e $\mathrm{R} \$$ 114,85/Toneladas, respectivamente.

\section{Gráfico 1 - Custo do vapor produzido na UIA (R\$/Tonelada)}

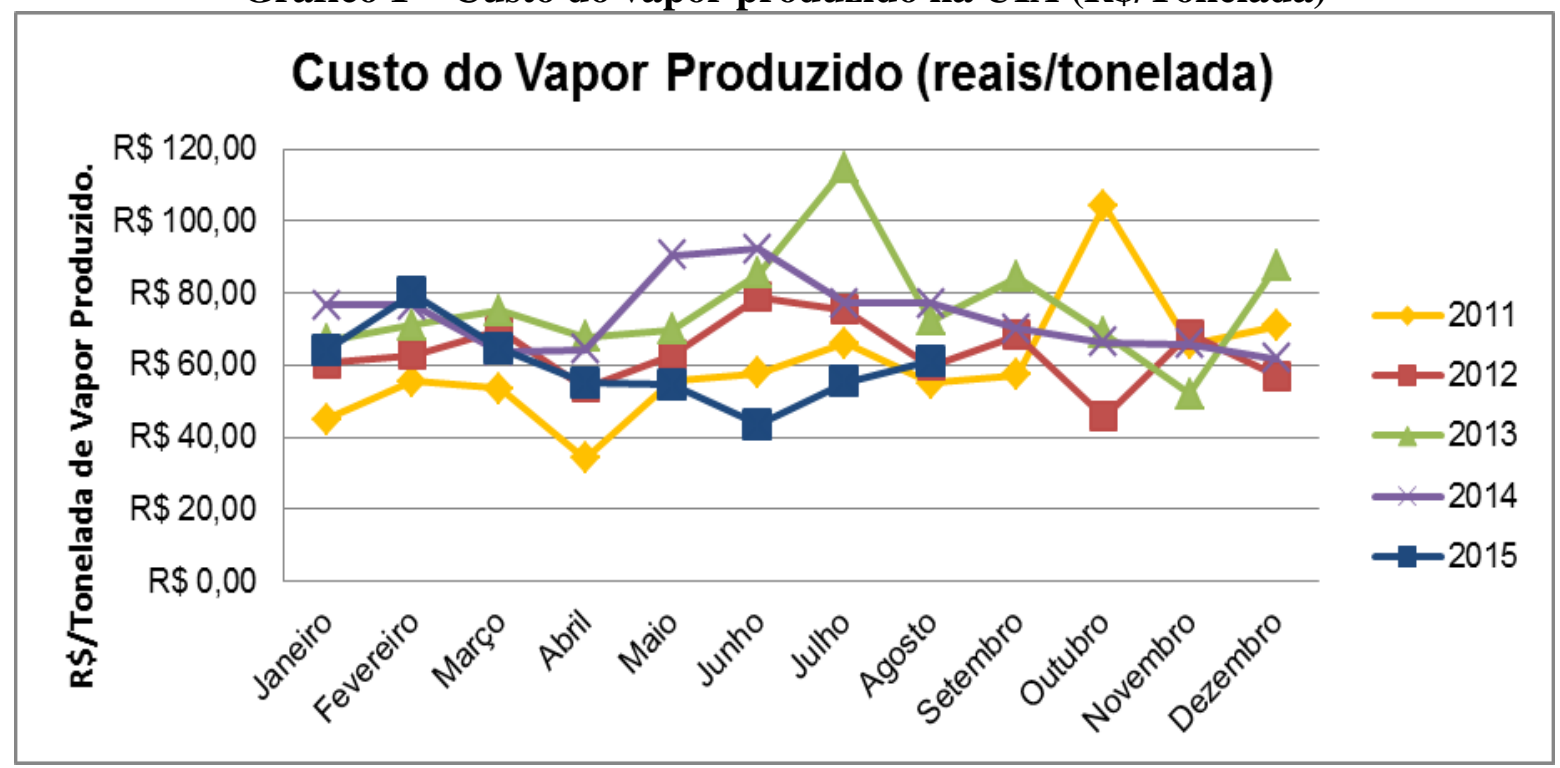

Fonte: Dados da pesquisa (2015).

A partir da análise da demanda de energia térmica produzida na caldeira e requerida pelo processo de produção industrial, no período entre janeiro 2011 e agosto de 2015, calculou-se a quantidade de vapor produzido na UIA. A partir desse cálculo, construiu-se o gráfico 2 , no qual se observa que, no citado período, houve a maior média de produção de vapor, equivalente a 7185,71 toneladas, o que, em hipótese, deveria gerar maior custo médio do vapor produzido. 


\section{Gráfico 2 - Média anual de vapor produzido na UIA (em Tonelada)}

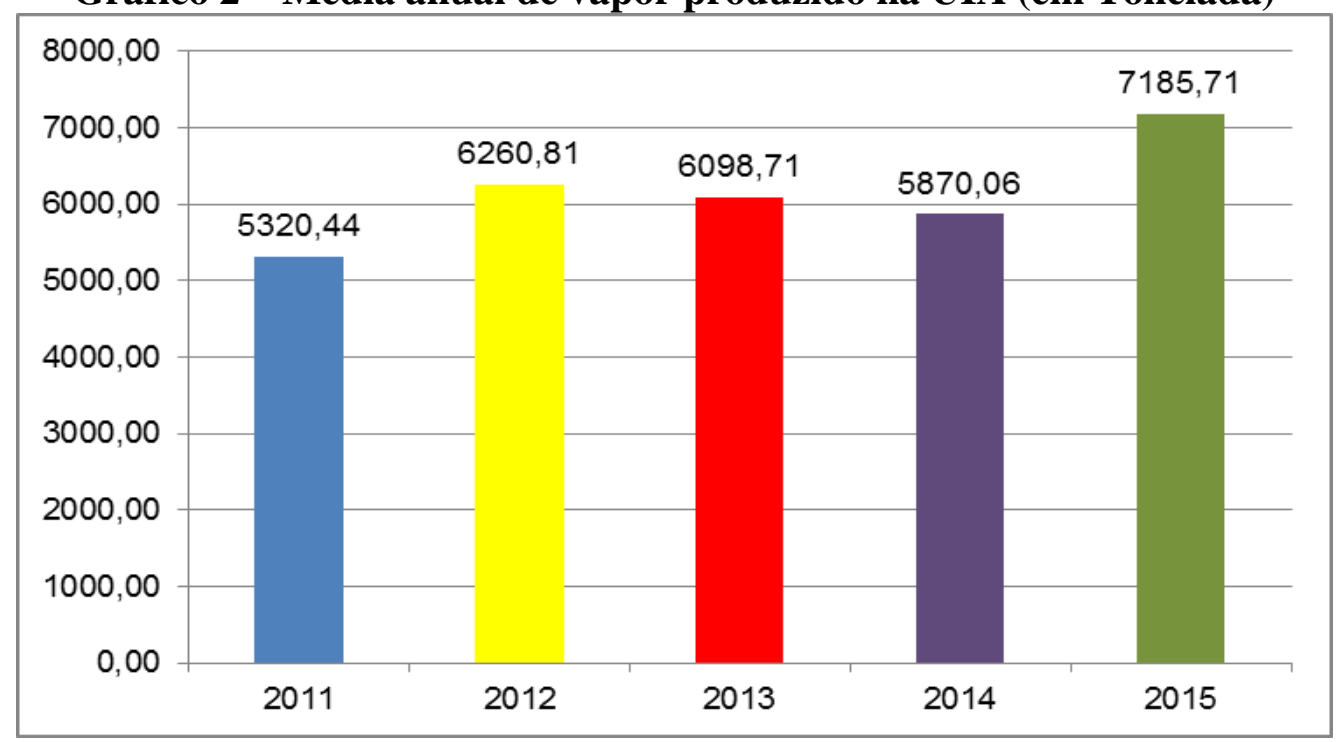

Fonte: Dados da pesquisa (2015).

Consideradas as variáveis umidade e preço da biomassa/cavaco (medidas só em 2015), calculou-se a média anual do custo da produção de vapor (em reais por toneladas, $\mathrm{R} \$ / \mathrm{T}$ ) entre janeiro $2011 \mathrm{e}$ agosto de 2015, apresentada no gráfico 3 . Notadamente, em 2013, a produção de vapor na
UIA alcançou o maior custo médio anual, $\mathrm{R} \$$ $73,43 / \mathrm{T}$, seguido por 2014 , com custo médio de $\mathrm{R} \$$ $73,62 / \mathrm{T}$. Entre janeiro e agosto de 2015, período desse estudo, a produção de vapor manteve o menor custo médio, R $\$ 59,83 / \mathrm{T}$. Na análise correlacional (gráficos 2 e 3 ) verifica-se maior produção de vapor por menor custo médio anual por tonelada.

Gráfico 3 - Custo médio anual da tonelada de vapor produzido na UIA

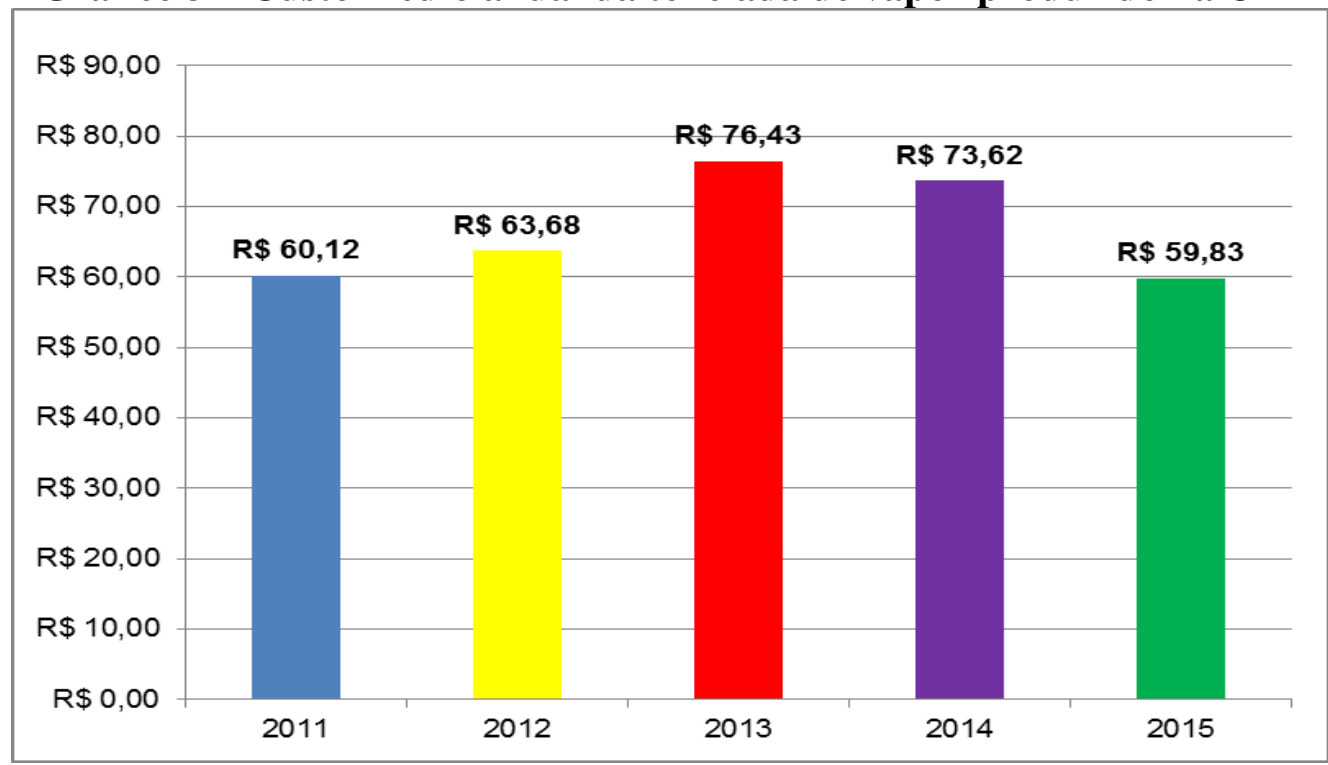

Fonte: Dados da pesquisa (2015).

Em função do escopo desse estudo, na análise comparativa da norma ISO 14000 e de desenvolvimento sustentável do Relatório Brundtland (1991), percebeu-se que a agroindústria investigada foca a dimensão ambiental da sustentabilidade empresarial na gestão ambiental centrada na prevenção e controle da poluição, uso racional de recursos naturais, atendimento à legislação ambiental, promoção de melhoria contínua do sistema de gestão ambiental.

Essa dimensão está associada à dimensão econômica da sustentabilidade que, na concepção de crescimento sustentável da agroindústria investigada, percebe os resultados econômicos e 
financeiros como suporte básico da dimensão social que se afirma na responsabilidade social das cooperativas, nas ações sociais para o desenvolvimento da comunidade local e no compromisso com a promoção dos recursos humanos. Portanto, essas três dimensões formam o tripé da sustentabilidade empresarial da UIA e, por extensão, do complexo agroindustrial objeto de análise deste estudo localizado no oeste do Paraná.

\section{Considerações Finais}

Com base nas condições em que se desenvolveu o estudo de caso na UIA do complexo agroindustrial cooperativista, conforme objetivos propostos, em relação à metodologia de recebimento/pagamento da biomassa/cavaco para a geração de energia térmica, a partir da análise dos dados, realizada de forma comparativa entre planilhas de produção/custo do vapor e as de produção industrial, conclui-se que essa metodologia alternativa é eficiente para diminuir o custo de produção do vapor na caldeira e atender a demanda de produção industrial da UIA.

Em função do escopo e das limitações desse estudo, considerada a família de normas ISO 14000, assim como por ser uma metodologia colocada em prática somente em 2015, porquanto, em fase experimental, os ganhos ambientais gerados pelo sistema de combustão da caldeira industrial ainda carecem de estudos mais específicos em uma ampla variedade de temas. Sugerem-se novas pesquisas que analisem os poluentes atmosféricos, e suas respectivas concentrações, emitidos durante $\mathrm{o}$ processo de combustão da biomassa/cavaco com menor teor de umidade para aquecimento da caldeira industrial da UIA. Em hipótese, a reunião dessas análises possibilitaria melhor compreensão acerca do significado e da contribuição dessa unidade produtora para o desenvolvimento sustentável e sustentabilidade dos ecossistemas e, principalmente, sobre a responsabilidade socioambiental desse complexo agroindustrial cooperativista.

\section{Referências}

ABNT. Associação Brasileira de Normas Técnicas. NBR ISO 14001. 2. ed. São Paulo: ABNT, 2004.
ABNT, 2005.

NBR ISO 14004. 2. ed. São Paulo:

ARAÚJO, G. C.; MENDONÇA, P. S. M. Análise do processo de implantação das normas de sustentabilidade empresarial: um estudo de caso em uma agroindústria frigorífica de bovinos. RAM. Revista de Administração Mackenzie. São Paulo, v. 10, n. 2, 2009.

ARRUDA, M. Z. Análise de combustíveis de caldeiras. Passo Fundo, RS: Universidade de Passo Fundo, 2009.

ABPA. Associação Brasileira de Proteína Animal. Balanço: ABPA prevê crescimento para os setores de aves e suínos em 2015. Disponível em: <http://sna.agr.br/balanco-abpa-prevecrescimento-para-os-setores-de-aves-e-suinosem-2015/>. Acesso em: 12 set. 2015.

AVISITE. Notícia. Exportadores de carne de frango em 2014 segundo a SECEX/MDIC. Disponível em: <http://avisite.com.br/noticias/>. Acesso em: 12 set. 2015.

BOFF, L. História da sustentabilidade. 2008. Disponível em: <http://www. coepbrasil.org. br/portal/Publico/ > . Acesso em: 15 set. 2015.

BRASIL. Ministério da Agricultura, Pecuária e Abastecimento. MAPA, Exportações. 2015. Disponível em: <http://www.agricultura.gov.br/animal/exportaca o>. Acesso em: 12 set. 2015.

Ministério de Estado do Trabalho e Emprego. Portaria no 594, de 28 de abril de 2014. Altera dispositivos da NR 13: caldeiras e vasos de pressão. Disponível em: <http://www.normaslegais.com.br/legislacao/por taria.htm>. Acesso em: 12 set. 2015. . Ministério do Meio Ambiente. Agenda

21. 2000. Disponível em: <http://www.mma.gov.br/responsabilidadesocioambiental/agenda-21/agenda-21-global>. Acesso em: 14 set. 2015.

Constituição Federal. 1988. Brasília, DF: CC, 2015.

Lei $\mathbf{n}^{\mathbf{0}} \mathbf{5 . 7 6 4}$, de 16 de dezembro de 1971 . Define a política nacional de cooperativismo, 
instrui o regime jurídico das sociedades cooperativas e dá outras providências. Brasília, DF: CC, 1971.

BRUNDTLAND, G. H. Nosso futuro comum: comissão mundial sobre meio ambiente e desenvolvimento. 2.ed. Rio de Janeiro: Fundação Getúlio Vargas, 1991.

CAPORAL, F. R.; COSTABEBER, J. A. Análise multidimensional da sustentabilidade: uma proposta metodológica a partir da Agroecologia. In: Agroecol. e Desenv. Rur. Sustent.. Porto Alegre, RS, v. 3, n. 3, p. 70-85, 2002.

CAVALCANTI, C. (org.). Meio ambiente, desenvolvimento sustentável e políticas públicas. São Paulo: Cortez, 2003.

CORAL, E. Modelo de planejamento estratégico para a sustentabilidade empresarial. Tese (Doutorado em Engenharia da Produção). Universidade Federal de Santa Catarina. Florianópolis: UFSC, 2002.

COSTABEBER, J. A.; CAPORAL, F. R. Possibilidades e alternativas do desenvolvimento rural sustentável. In: VELA, H. (Org.) Agricultura familiar e desenvolvimento rural sustentável no Mercosul. Santa Maria: UFSM, 2003, p. 157-94.

ECOFORT. Empresa Brasileira de Bioenergia. Produtos. 2014. Disponível em: <http://ecofortebioenergia.com.br/produtos.asp>. Acesso em: 20 out. 2015.

GIL. A. C. Métodos e técnicas de pesquisa social. 6. ed. São Paulo: Atlas, 2008.

GUIMARÃES, R. La sostenibilidad del desarrollo entre Rio-92 y Johaneburgo 2002: eramos felices y no sabiamos. In: Ambiente y Desarrollo. Bogotá, Colombia, v XVIII, n. 1, p. 60-9, mar. 2002.

HART, S. L. Strategies for a sustainable world. Vestas Modern Energy. Harvard Business Review. v. 75, n.1, 1997.
IEA-APTA. Instituto de Economia Agrícola. Índice médio de preço de eucalipto para o produtor, mensal e acumulado. 2015. Disponível em: <http://www.iea.sp.gov.br/out/florestas.php>. Acesso em: 15 set. 2015.

KOSLOVSKI, J. P. A cooperação e a responsabilidade social no Paraná. Paraná Cooperativo. Curitiba, PR, a. 2, n. 17, p. 3-11, jan. 2006.

LIMA, E. A. Alternativa para estimar o preço da madeira para energia. In: Comunicado Técnico 260. Colombo, PR: Embrapa, 2010.

MAGRINI, A. Política e gestão ambiental: conceitos e instrumentos. Revista Brasileira de Energia. Itajubá, MG, v. 2, n. 2, p. 1-8, 2001.

MARCONI, M. de A.; LAKATOS, E. M. Fundamentos de metodologia científica. 6 ed. São Paulo: Atlas, 2007.

POMBO, F.; MAGRINI, A. Panorama de aplicação da norma ISO 14001 no Brasil. Gestão \& Produção. São Carlos, SP, v. 15, n. 1, p. 1-10, 2008.

RODRIGUES, R. M. Pesquisa acadêmica: como facilitar o processo de preparação de suas etapas. São Paulo: Atlas, 2007.

SACHS, I. Caminhos para o desenvolvimento sustentável. Rio de Janeiro: Garamond, 2000.

SALUM, A. D. Eficiência energética em sistema de combustão de caldeira. Salvador: Universidade Federal da Bahia, 2011.

SILVA, C. L. da; MENDES, J. T. G. (Orgs.). Reflexões sobre o desenvolvimento sustentável: agentes e interações sob a ótica multidisciplinar. Petrópolis: Vozes, 2005.

UNEP. United Nations Environment Program. Resource efficient and cleaner production. 2015 [2003]. Disponível em: <http://www.unep.fr/scp/cp/>. Acesso em: 15 set. 2015. 